\title{
Understanding the Dominant Factors towards the Intention to Use Youtube continuously in Indonesia
}

\author{
Nur Cahyo Wibowo ${ }^{1}$, Tri Lathif Mardi Suryanto, Asif Faroqi, Rizka Hadiwiyanti \\ Information System \\ Universitas Pembangunan Nasional "Veteran" Jawa Timur \\ Surabaya, Indonesia \\ ${ }^{1}$ nurcahyo.si@upnjatim.ac.id
}

\begin{abstract}
YouTube as the world's largest video content service provider that can be accessed by various groups of people provides facilities to share videos easily widely to its consumers. With the development of YouTube as a social network site (SNSs), this study aims to identify the motivations of consumers who wish to participate in SNSs, as well as examine the effect of the relationship of facilities to intention to use through the perspective of Uses \& Gratification (U \& G). Data collection was carried out by distributing online questionnaires with non-probability sampling techniques to obtain empirical testing from the research model. The findings of identification of self-presentation (SP), passing time (PT), and information sharing (IS), Enjoyment (Enjoy), and media appeal (MA) are motives that support the condition of continuance intention (CI). The results of the study confirm that appeal gratification media and enjoyment of gratification as gratuities are needed by YouTube users to strengthen continuance intention.
\end{abstract}

Keywords-SNSs, U\&G, Media Appeal, continuance Intention.

\section{INTRODUCTION}

Since the social media era is growing in Indonesia, they show themselves as a strong influencer in changing communication styles, including YouTube. According to [1] YouTube is the most popular social media in Indonesia. Past researchers about the Internet and Social Media agreed that social media lifestyle is changing the way people making their journals, sharing experiences, and getting more information even further than before [2], [3], [4], [5], [6]. This shows us that our society is inclined to share interesting information, even if that is their personal information. That makes even simpler for people to collect and reshare exciting information's.

YouTube is a social media provider which offers a lot of video content for almost every aspects. Sports, educations, business, entertainment, etc. Can easily find, saved, and shared by YouTube [7]. In another further research about YouTube and our society, we find that every month, people watching more than 6-million-hour video and also every minutes, more than a hundred hours of video is being uploaded [4]. Because of YouTube user frequency, the growth of social media in our society makes social media as a useful tool in communication, content creating, sharing, and business growth [8].

Reference [9] finds that YouTube popularity in Indonesia in 2017 is under Facebook as the second world's biggest social media. But in 2018, YouTube is being the biggest social media in Indonesia. Because of the using of social media dynamics and cultural technology research, there are a lot to study about why and how the user's intention to participating and also sharing information in Youtube. Reference [7] stated that design of socio-technical is the considerable study to discuss the connection between YouTube and its users.

With Youtube appeal as the most popular social media in Indonesia, it gives many differences to influencing YouTube's users. The wide distinction is allowing YouTube to understand their users with Uses and Gratification Work Frame (U\&G) [5], [7], [9]. U\&G is a reliable work frame for running the research to see the personality and psychological needs and personal gratification [10].

The research about YouTube's popularity in Indonesia is aiming to give contribution about better understanding to user's dominant factor for sharing, commenting, like and disliking contents. By this quantitative inferential research and questionnaire-based method, it gives researches focus on the relationship between user's participation and facilities utilization by Youtube.

\section{LITERATURE REVIEW}

\section{A. YouTube Social Network Site}

YouTube is a social media site established in 2005, this site is providing video content to allow the users to post, watching, liking, commenting, sharing, and linking videos. YouTube can give many videos which give reviews, demos, advertisers amateurs, and professionals video, but the more popular is YouTube not only giving videos, but it also gives the room for users to make and upload vlog and tutorial videos and even saving their personal preference video. Past research agreed that YouTube has unique architecture, policy, and culture which allowed their users to make their own representation in using YouTube [11].

The diversity of YouTube is used not only for fun but also for social interactions by comments, searching and giving information's [7]. By this diversity, according to [1] YouTube as SNSs is in the top position in Social Media Popularity in Indonesia, YouTube's appeal is considering as good to being an alternative option in searching entertainment, fun, 
communication, personal actualization, and also being a media for information sharing.

YouTube's popularity is boosting global user's interaction and participation. Almost every internet users in Indonesia ever using YouTube. This can be proved by the survey held in 2017. Social media is taking the first place in internet usages lifestyles [12]. YouTube is providing many functions besides uploading and watching videos, which encourages the users to be involved in the site. YouTube is allowing the content to share between the users, linked to the desired URL, and being discussed in the comment section [13].

That interesting point makes the researchers considering that YouTube is important in information confirmation about the connection between YouTube and the users, and also what makes YouTube is popular among their users.

\section{B. Uses \& Gratification Framework}

Because the topic around social Information System is getting more interesting, there are a lot of researchers adopting Uses and Gratification (U\&G) theory as a framework for doing an empirical review about social media user's behavior. Past researches [2], [5], [9], [14], [15], [16], [17], [18] is using U\&G as the framework for doing the observation about social media behavior such as Facebook, Twitter, SNSs, Blogging. Thus, $\mathrm{U} \& \mathrm{G}$ is considered as the fittest theory in this research as a framework to observe users' terms for choosing YouTube as social media which used continuously. U\&G theory helps us understand about media usages in personal level and also learning about their IS usage motives [17].

Past research [17] has succeeded to modify U\&G work frame, presenting $U \& G$ in 3-dimensional gratifications: first, hedonic gratification; second, social gratification, and third, utilitarian gratification. Further researchers [5] is completing the previous framework by [17] by adding technology gratification. By this new U\&G framework, technology gratification is being the latest findings which giving research opportunity to use it as a mediation factor for another three gratification dimension. Media appeal is the reflections of technology gratification dimension [5].

Media appeal is the media skill in giving perceptions of easiness and limitless communication between users, limitless accessibility. Thus media appeal is a must for evolving social media platform. One of the most important impacts for behavior impact of usage is media appeal [3] then further research gives the value about media appeal, as [5]. They see that media appeal potential power as a booster of people's intention of social media continuous usage. Hereby, this research assuming that technological gratification is reflected by media appeal is contributing to boosting the user's intention to use YouTube repeatedly is proper to observe. By adopting past researchers $\mathrm{U} \& \mathrm{G}$ work frame, this research is aiming to observe threedimensional gratifications: first, hedonic gratification; second, utilitarian gratification; and technology gratification as important factors for YouTube user's continuance intention in Indonesia.

\section{RESEARCH METHODS AND HYPOTHESIS}

\section{A. Data collection and sampling}

This research is aiming at Indonesian YouTube users. Thus this research is doing an online survey by spreading online questionnaire by Google Form. Population amount decided is 143.260.000 Indonesian internet users, as in APJII [12] about internet user's penetration in Indonesia 2017, for further we decide our respondent amount by Slovin Formula:

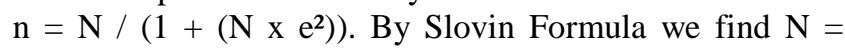
$143.260 .000 .000 /(1+(143.260 .000 \times(0.05) 2))=399,999$ for further counted as 400 sample. This research is collecting 475 respondent but then eliminating respondents who do not have YouTube account. For best results, we use Uses and Gratification (U\&G) literature study as a basic experiment model analysis framework. This research is using WarpPLS 5.0 software for data computing and statistic method by Path Analysis.

\section{B. Instruments and measures}

The measuring instrument uses in this research is the survey including questions for better personal characteristics understanding from YouTube user's respondent sample. There are 30 questions given to the respondents for measuring YouTube usage frequentation, and how to use it. The questionnaire scale is using Likert Scale by strongly disagree, disagree, neutral, agree, and strongly agree. Thus the questions given in this questionnaire is about U\&G [5] which is: Passing Time (PT), Enjoyment (Enjoy), Information Sharing (IS), SelfPresentation (SP), and Media Appeal (MA), and Continuance Intention (CI) for further deciding validation testing score and the reliability that is validation test using factor loading directive $>0,361$. The number is gained from the amount of $r$ table from 30 respondents with $0.5 \%$ tolerance; it is valid if Alpha $>0,361$.

\section{Research Mode}

For this research needs, we found it important to giving hypothetical model from literature study we found from past research [5], [7], [9], [19], so we found modified framework U\&G usages for SNSs research in Indonesia. We found 4 free variables that are Passing Time (PT), Enjoyment (Enjoy), Information Sharing (IS), Self-Presentation (SP) and 2 tied variable that is Media Appeal (MA) and continuance Intention (CI). Figure 1 is our hypothetical research model. 


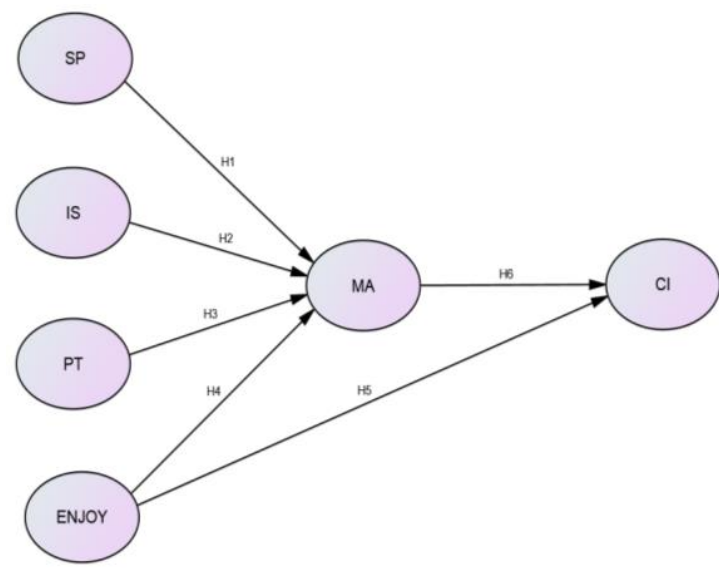

Fig. 1. Research model hypothesis

H1: Self-Presentation is influencing Media Appeal

$\mathrm{H} 2$ : Information sharing is influencing Media Appeal

H3: Passing Time is influencing Media Appeal

H4: Enjoyment is influencing Media Appeal

H5: Enjoyment is influencing Continuance Intention

H6: Media Appeal is influencing Continuance Intention

\section{RESULT AND DisCUSSION}

\section{A. Data Analysis}

From our computed data results we have done to the respondent's majority, our participants are 54\% male and $46 \%$ female. Java and Bali are contributing the most respondents with $336(84 \%)$, Sumatra island with $27(6.75 \%)$, Kalimantan island with $14(3.5 \%)$, Sulawesi island with $14(3.5 \%)$, and the last Papua with $9(2.25 \%)$.

Computed data are shown in table 1. Is explaining about teenage users is dominant in this research that is as much as 314 respondent $(78.5 \%)$ teenagers, and the biggest respondent's education level is Senior High Schools as much as 303 respondent $(75.75 \%)$, and the biggest respondent state is college students as much as $271(67.75 \%)$ and private workers as much as 90 people $(22.5 \%)$.

\section{B. Measurement Model and Hypothesis}

For evaluating the measurement model, this research is using convergent validity test and discriminant test. Convergent validity test is measuring whether the questions is effectively showing the exact factor(s), scored by composite reliability (CR) scored above 0,7 , besides the question items reliability in the variables is shown by segmented question items scoring, in other words, by seeing the average variance extracted (AVE) that is showing score above 0.5 [20], [21], [22]. The scoring points are shown in Table 2.
TABLE I. DEMOGRAPHIC INFORMATION OF RESPONDENTS (N=400)

\begin{tabular}{|c|c|c|}
\hline \multicolumn{2}{|c|}{ Respondent's Data } & \multirow{2}{*}{$\begin{array}{c}\text { Total } \\
218 \\
\end{array}$} \\
\hline Sex & Male & \\
\hline & Female & 182 \\
\hline \multirow[t]{4}{*}{ Age } & Teenage & 314 \\
\hline & Youth & 82 \\
\hline & Elder & 4 \\
\hline & Eldest & 0 \\
\hline \multirow[t]{5}{*}{ Education Level } & Below SMP & 47 \\
\hline & SMA/SMK & 303 \\
\hline & Diploma & 17 \\
\hline & $\mathrm{S} 1$ & 30 \\
\hline & $\mathrm{S} 2$ & 3 \\
\hline \multirow[t]{4}{*}{ State } & College Students & 271 \\
\hline & Gov. Worker & 12 \\
\hline & Private Worker & 90 \\
\hline & Entrepreneur & 27 \\
\hline \multirow[t]{5}{*}{ Domicile } & Jawa-Bali & 336 \\
\hline & Sumatera & 27 \\
\hline & Kalimantan & 14 \\
\hline & Sulawesi & 14 \\
\hline & Papua & 9 \\
\hline
\end{tabular}

TABLE II. CONSTRUCT RELIABILITY AND VALIDITY

\begin{tabular}{|l|c|r|r|r|r|r|l|l|}
\hline & $\begin{array}{c}\text { AV } \\
\text { E }\end{array}$ & CR & SP & PT & IS & $\begin{array}{c}\text { ENJO } \\
\text { Y }\end{array}$ & MA & CI \\
\hline & & 0.8 & $\mathbf{0 . 7}$ & & & & & \\
SP & 0.50 & 5 & $\mathbf{0}$ & & & & & \\
\hline & & 0.9 & 0.2 & $\mathbf{0 . 8}$ & & & & \\
PT & 0.76 & 0 & 1 & $\mathbf{7}$ & & & & \\
\hline & & 0.9 & 0.3 & 0.3 & $\mathbf{0 . 8}$ & & & \\
IS & 0.70 & 0 & 2 & 7 & $\mathbf{3}$ & & & \\
\hline & & 0.8 & 0.3 & 0.2 & 0.3 & & & \\
ENJOY & 0.58 & 0 & 0 & 3 & 3 & $\mathbf{0 . 7 6}$ & & \\
\hline & & 0.8 & 0.2 & 0.5 & 0.4 & & & \\
MA & 0.75 & 6 & 0 & 0 & 7 & 0.46 & $\mathbf{0 . 8 6}$ & \\
\hline & & 0.7 & 0.1 & 0.4 & 0.3 & & & \\
CI & 0.59 & 4 & 0 & 9 & 5 & 0.44 & 0.37 & $\mathbf{0 . 7 7}$ \\
\hline
\end{tabular}

In table 2 also showed discriminant validity point, discriminant validity is used as instrument quality scoring in questionnaire's measuring tools, by condition of square root scoring of AVE > correlation between indicators (Ghozali, 2014). In table 2, showed that SP scoring is $0.70>0.05$, PT 0.87 $>0.76$, IS $0.83>0.70$, ENJOY $0.76>0.58$, MA $0.86>0.75$, and the last $\mathrm{CI} 0.77>0.59$. It means the quality from question instruments spread is qualified enough for the formulated factors. Next, in table 3 showed Combined loadings score to see the reliability points from measurement tools we spread to the respondents. 
TABLE III. COMBINED LOADINGS

\begin{tabular}{|c|c|r|r|r|r|c|}
\hline & \multicolumn{1}{|c|}{ SP } & \multicolumn{1}{c|}{ PT } & \multicolumn{1}{c|}{ IS } & ENJOY & \multicolumn{1}{c|}{ MA } & CI \\
\hline SP1 & 0.654 & 0.202 & 0.01 & 0.14 & -0.356 & -0.041 \\
\hline SP2 & 0.707 & 0.132 & -0.076 & -0.14 & 0.114 & -0.021 \\
\hline SP3 & 0.713 & -0.077 & -0.1 & -0.287 & 0.322 & 0.045 \\
\hline SP4 & 0.748 & 0.11 & -0.109 & 0.276 & -0.172 & -0.11 \\
\hline SP7 & 0.706 & -0.12 & 0.132 & 0.046 & -0.051 & 0.053 \\
\hline SP8 & 0.691 & -0.243 & 0.155 & -0.039 & 0.127 & 0.079 \\
\hline PT1 & -0.052 & 0.853 & 0.031 & -0.071 & 0.029 & -0.146 \\
\hline PT2 & 0.029 & 0.889 & -0.022 & -0.036 & -0.101 & 0.186 \\
\hline PT3 & 0.021 & 0.878 & -0.007 & 0.106 & 0.075 & -0.047 \\
\hline IS1 & -0.097 & -0.341 & 0.832 & -0.008 & 0.078 & 0.112 \\
\hline IS2 & 0.019 & -0.045 & 0.885 & -0.016 & 0.011 & 0.003 \\
\hline IS3 & 0.075 & 0.124 & 0.859 & 0.01 & -0.107 & -0.017 \\
\hline IS4 & -0.001 & 0.28 & 0.775 & 0.016 & 0.021 & -0.105 \\
\hline E1 & 0.053 & -0.172 & -0.127 & 0.737 & -0.046 & -0.145 \\
\hline E2 & 0.003 & 0.163 & 0.184 & 0.793 & -0.047 & -0.257 \\
\hline E3 & -0.054 & -0.003 & -0.068 & 0.762 & 0.093 & 0.408 \\
\hline MA1 & -0.061 & 0.167 & 0.051 & -0.033 & 0.869 & -0.005 \\
\hline MA2 & 0.061 & -0.167 & -0.051 & 0.033 & 0.869 & 0.005 \\
\hline CI1 & -0.006 & -0.162 & -0.017 & 0.333 & 0.077 & 0.774 \\
\hline CI2 & 0.006 & 0.162 & 0.017 & -0.333 & -0.077 & 0.774 \\
\hline
\end{tabular}

A test is reliable if measuring requirements at its testing tools shows empirically credible evidences. By using Alpha score requirement $>\mathrm{r}$ table $5 \%(0.3)$ those questions instruments are reliable and valid and also consistent as a measurement tool. Thus in table 3 showed that Alpha score that is mostly bigger than $\mathrm{r}$ point table $5 \%$, by that the measurement tools used is appropriate for being research's measuring tools.

TABLE IV. MODEL FIT AND QUALITY INDICES

\begin{tabular}{|l|c|}
\hline \multicolumn{1}{|c|}{ Measurement } & Value \\
\hline Average path coefficient (APC) $=0.253, \mathrm{P}<0.001$ & Good \\
\hline Average R-squared (ARS) $=0.356, \mathrm{P}<0.001$ & Good \\
\hline Average adjusted R-squared (AARS) $=0.351, \mathrm{P}<0.001$ & Good \\
\hline $\begin{array}{l}\text { Average block VIF (AVIF) }=1.243, \text { acceptable if }<=5 \text {, ideally } \\
<=3.3\end{array}$ & Ideally \\
\hline $\begin{array}{l}\text { Average full co linearity VIF }(\mathrm{AFVIF})=1.550, \text { acceptable if } \\
<=5, \text { ideally }<=3.3\end{array}$ & Ideally \\
\hline $\begin{array}{l}\text { Tenenhaus GoF }(\mathrm{GoF})=0.481, \text { small }>=0.1, \text { medium }>=0.25, \\
\text { large }>=0.36\end{array}$ & Large \\
\hline
\end{tabular}

In table 4 we showed Fit Model Results in this research. Fit Model Research is heading to give an observation about commonly results output. Observation technique is adjusted with past research [20], [21], [22]. In this research we find the ideal fit model score by seeing Average path coefficient (APC), Average R-squared (ARS), and Average adjusted R-squared (AARS) scores are showing $\mathrm{P}$ scores $<0.001$ by scoring $\mathrm{APC}=$ 0.253 , ARS $=0.356$, AARS $=0.351$ and we also doing multicolinearity measurements by observing output results from Average block VIF (AVIF) and Average full colinearity VIF (AFVIF) smaller than $<=3.3$, by VIF scoring $=1.243$ and $\mathrm{AFVIF}=1.550$ that means there is no problems with data spreading which leads to multi colinearity between indicators and between latent variables. Thus Goodness of Fit $(\mathrm{GoF})$ point result is $>=0.36$, by scoring 0.481 which means Fit Model result is very good.

In table 5 shown the information about standard error which giving Standard Error minimal requirement point is $<0.05$, by virtue of output results we found that standard error scored from the connection between $\mathrm{SP} \rightarrow \mathrm{MA}=0.046$, standard error from the connection between $\mathrm{PT} \rightarrow \mathrm{MA}=0.044$, standard error from the connection between IS $\rightarrow \mathrm{MA}=0.045$, standard error from the connection between ENJOY $\rightarrow \mathrm{MA}=0.04$, standard error from the connection between ENJOY $\rightarrow \mathrm{CI}=0.082$, and standard error from the connection between $\mathrm{CI} \rightarrow \mathrm{MA}=0.049$.

TABLE V. STANDARD ERRORS FOR PATH COEFFICIENTS

\begin{tabular}{|l|c|c|c|r|r|l|}
\hline & SP & PT & \multicolumn{1}{c|}{ IS } & ENJOY & MA & CI \\
\hline MA & 0.046 & 0.044 & 0.045 & 0.04 & & \\
\hline CI & & & & 0.082 & 0.049 & \\
\hline
\end{tabular}

Further, we see effect size at this research. Effect size is measurement about practical significance research results shown as the correlation effect measurement between variables. Effect size also considered as the meaning measurement from research in a practical stage [20], [21], [22]. In table 6, the columns are indicated as effect size for every latent variable indication. The recommended score is $0.000-0.010$ in small category, $0.022-0.059$ in medium category, $0.083-0.500$ in large category [23].

TABLE VI. EFFECT SIZES FOR PATH COEFFICIENTS

\begin{tabular}{|l|c|c|c|r|r|l|}
\hline & SP & IS & PT & ENJOY & MA & CI \\
\hline MA & 0.004 & 0.197 & 0.126 & 0.128 & & \\
\hline CI & & & & 0.161 & 0.085 & \\
\hline
\end{tabular}

Table 6 is giving outlines about the effect scores happened because of the connection between latent variables. Effect size resulted by $\mathrm{SP} \rightarrow \mathrm{MA}=0.004$, means $\mathrm{SP}$ is having a weak correlation with MA, effect size resulted by IS $\rightarrow \mathrm{MA}=0.197$, means Information Sharing is having enough correlation with $\mathrm{MA}$, effect size resulted by $\mathrm{PT} \rightarrow \mathrm{MA}=0.128$, means $\mathrm{PT}$ 
having enough correlation with MA, effect size resulted by $\mathrm{ENJOY} \rightarrow \mathrm{MA}=0.128$, means ENJOY is having weak correlation MA, effect size resulted by ENJOY $\rightarrow \mathrm{CI}=0.161$, means PT is having strong correlation with CI, effect size resulted by $\mathrm{MA} \rightarrow \mathrm{CI}=0.085$, means $\mathrm{MA}$ having strong correlation with $\mathrm{CI}$.

After grading the connection between factors, this research is using model results output to give more comprehensive correlation between factors to observe path analysis. Below is the output model research.

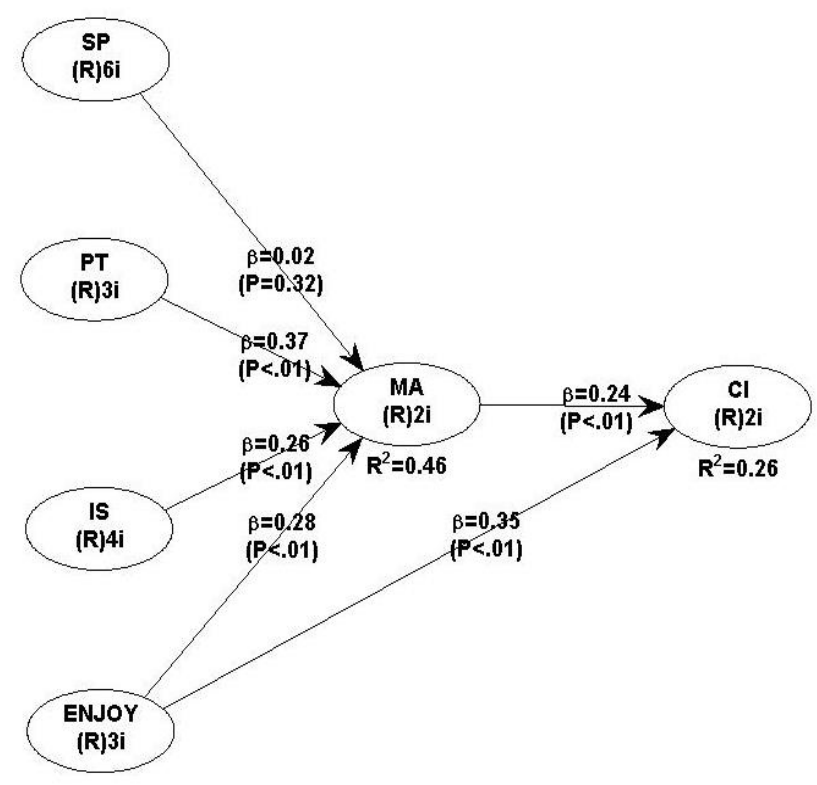

Fig. 2. Research Model Result

TABLE VII. RESULT HYPOTHESIS

\begin{tabular}{|c|l|c|c|c|}
\hline $\mathbf{H}$ & Correlation & $\boldsymbol{\beta}$ & $\mathbf{P}$ & Result \\
\hline $\mathrm{H} 1$ & $\mathrm{SP} \rightarrow \mathrm{MA}$ & 0.021 & 0.032 & Not Support \\
\hline $\mathrm{H} 2$ & $\mathrm{PT} \rightarrow \mathrm{MA}$ & 0.365 & $<0.001$ & Support \\
\hline H3 & IS $\rightarrow$ MA & 0.265 & $<0.001$ & Support \\
\hline H4 & ENJOY $\rightarrow$ MA & 0.276 & $<0.001$ & Support \\
\hline H5 & ENJOY $\rightarrow$ IC & 0.353 & $<0.001$ & Support \\
\hline H6 & MA $\rightarrow$ IC & 0.240 & $<0.001$ & Support \\
\hline
\end{tabular}

Explanation about picture 2 and table 7 is P-value and Beta $(\beta)$ scoring approximation using model results. In this research, the structural model is being tested using bootstrapping 500 technique. Picture 2 is showing a suitable coefficient line and significance level. In this research, the model output result is able to explain $26 \%$ variants used whereas another $74 \%$ is explainable using another variant that is not discussed in this research. By this, further intention for using YouTube in this research is showing the connection between $\mathrm{SP} \rightarrow \mathrm{MA}=$ having $\beta$ score $=0.02$ and $\mathrm{P}$-value score is $=0.32$, connection between $\mathrm{PT} \rightarrow \mathrm{MA}=$ having $\beta$ score $=0.37$ and $\mathrm{P}$-value score is $=<0.01$, connection between IS $\rightarrow \mathrm{MA}=$ is having $\beta$ score $=0.26$ and $\mathrm{P}$ - value score is $=<0.01$, the connection between ENJOY $\rightarrow$ MA $=$ is having $\beta$ score $=0.28$ and $\mathrm{P}$-value score is $=<0.01$, the connection between ENJOY $\rightarrow \mathrm{CI}=$ is having $\beta$ score $=0.35$ and $\mathrm{P}$-value score is $=<0.01$, the connection between MA $\rightarrow$ $\mathrm{CI}=$ is having $\beta$ score $=0.24$ and $\mathrm{P}$-value score is $=<0.01$. The explanation from model picture is showing that the intention to continue using YouTube is indirectly affected by 3 factors that are passing time perception, information sharing perception, enjoyment perception, meanwhile and the intention to continue using YouTube is directly affected by 2 factors that are enjoyment perception and media appeal perception. It is supporting H2, H3, H4, H5, H6 hypothesis, but unexpectedly, in this case, $\mathrm{H} 2$ is not approved that means self-presentation isn't having a significant impact or bigger contribution about the intention to continue using YouTube.

\section{Discussion}

This research is investigating about impact factors which impacting personal intention to continue using YouTube in Indonesia [16, [17]. There are 4 type of gratification that is hedonic gratification, Social gratification, Utilitarian gratification, and technology gratification, which further in this research only used 3 of gratification type which seems fit enough with this research that is utilitarian gratification, represented by self-presentation and information sharing factors, and hedonic gratification represented by passing time and enjoyment factor, meanwhile technology gratification is represented by media appeal factor. From that explanation, results are showing that there are three kinds of satisfaction which having significant impact on YouTube in Indonesia. Further discussed, utilitarian gratification which supporting YouTube continuous usage is information sharing, in the other hand 2 factors from hedonic gratification that is passing time and enjoyment is giving continuous impact in YouTube usage, and also technology gratification which represented by media appeal factor is able to produce effects to YouTube continuous YouTube usage.

In this research we find the results that are showing indirect impact on YouTube continuous usage that is passing time, information sharing, and enjoyment, this research result is linear with past research result [2], [5], [15], [17], [18] that passing time, information sharing, and enjoyment factor is having the chance to impacting continuance intention in using YouTube. This gives evidence that most of the users are spending the time to enjoying uploaded YouTube video, and also the users is personally accepting the easiness for using YouTube as a communication media to sharing and gaining information by watching useful videos.

It is in line with past research [5] [14], [15], [16], [17], [18] next finding is media appeal factor is significantly influencing continuance intention directly, but what is more interesting is enjoyment factor which in this research being spurious factor, we find out that enjoyment is impacting continuance intention both directly and indirectly. Further found that $\beta$ value from enjoyment is more significant than the $\beta$ value of media appeal. It shows that YouTube as a video content server is having its 
appeal in usefulness and also personally, this social media is counted as giving fun and even useful experience for users.

Last self-presentation findings which found being contradictive with this research hypothesis. Self-presentation is found in not having strong enough contribution to continuance intention, this finding is quite shocking at first but if we observe it further in past research [5], [17] self-presentation is not having contribution, in the self-presentation section this research is observing about how far is the chance for YouTube users helping themselves making their own personality which is impacting on how other people see and treat them. This proves that although Indonesian Vlogger is much empirically it doesn't give evidence that that video is for upgrading themselves. There is social influencer role as another factor to explain in other research.

\section{IMPLICATION AND LIMITATIONS}

In common, this research is found that personal user's intention to continue using YouTube is positively influenced by media appeal and enjoyment, but between those two factors, enjoyment is found as more dominant factor which can influence people for using YouTube continuously. By this, media appeal and enjoyment proof as influenced factors are approved, means YouTube is having good media appeal power and also having enjoyment affect to personal users so YouTube in this condition is able to give easiness access perception along with pleasure during the usage, such as YouTube is accessible from browser or smartphone, YouTube is giving offline playback options, which it is good for YouTube users. They can comment on a video, giving thumb Up on a video, sharing a video with others, and in the end, YouTube is affecting its users to feel happy while using it.

Even if this research is giving some interesting results, many restrictions are there to admit. First of all, this research data is collected from YouTube users using nonprobability sampling. We suggest for further research whom using our model results is researching with probability sampling method or other which sees as suitable for every research needs. Second, our study here is not observing active user and passive users in social media. Further research is encouraged to make it possible to find the chance of active and passive user's impact for social media. Third, in this research we are not doing social influence study, with our results, we suggest that social influence study is better being observed as an influencing factor for continuance intention.
[4] F. Khan, G.,\& S. Vong, "Virality over YouTube: an empirical analysis," Internet. Res., Vol. 24 Iss 5, pp. 629-647, 2014.

[5] C. Gan, \& H. Li, "Understanding the effects of gratifications on the continuance intention to use WeChat in China: A perspective on uses and gratifications", Comput. Hum. Behav., 2017.

[6] J.E. Klobas, T.J. McGill, S. Moghavvemi \& T. Paramanathan, "Compulsive YouTube usage: A comparison of use motivation and personality effects", Comput. Hum. Behav., 2018

[7] M. Laeeq Khan, "Social media engagement: What motivates user participation and consumption on YouTube", Comput. Hum. Behav. vol 66, 236-247, 2017.

[8] A.M. Kaplan, and M. Haenlein, "Users of the world, unite! The challenges and opportunities of social media", Bus. Horizons, Vol. 53 No. 1, pp. 59-68, 2010.

[9] T.L.M. Suryanto, N.C. Wibowo, S.A. Ithriah, A. Faroqi, D. Fatkhur, "Why Indonesian users visiting YouTube an exploration of uses and gratification theory," Proc. Int. Jt. Conf. on Sci. and Tech. (IJCST) 2017, ISBN: 978-602-99806-3-9, 2017.

[10] J.G. Blumler, \& E. Katz, "The uses of Mass Communications: Current perspectives on gratifications", 1974

[11] A.N. Smith, E. Fischer, \& C. Yongjian, "How does brand-related user generated content differ across YouTube, Facebook, and Twitter?" J of Interact. Marks., vol 26(2),pp 102-113, 2012.

[12] APJII, "Penetration and Behavior of Indonesian Internet Users in 2017", Indonesia Internet Serv. Prov. Assoc., 2017

[13] J.E. Burgess, \& J.B. Green, "The entrepreneurial vlogger: Participatory culture beyond the professional-amateur divide". YouTube Read., pp. 89107,2009

[14] Y.-C. Ku, T.-H. Chu, \& C.-H.Tseng, "Gratifications for using CMC technologies: A comparison among SNS, IM, and e-mail." Comput. in Hum. Behav., 29(1), 22 -234, 2013.

[15] C.K. Coursaris, S. Jieun, O.W. Van, \& Y. Younghwa, "Disentangling Twitter's Adoption and Use (Dis) Continuance: A Theoretical and Empirical Amalgamation of Uses and Gratifications and Diffusion of Innovations.”, AIS Trans. Hum.-Comput. Interact., vol 5(1), 57-83, 2013.

[16] C. Gan, \& W. Wang, "Uses and gratifications of social media: a comparison of micro blog and WeChat". J. of Syst. and Inf. Tech., 17(4), 351-363, 2015.

[17] H. Li , Y. Liu, X. Xu, J. Heikkilä, \& H. van der Heijden, "Modeling hedonic is continuance through the uses and gratifications theory: An empirical study in online games". Comput. in Hum. Behav., vol. 48, pp 261-272, 2015.

[18] W. Chaouali, "Once a user, always a user: Enablers and inhibitors of continuance intention of mobile social networking sites.", Telemat. and Inform, vol. 33(4), 1022-1033, 2016.

[19] Y. Wook, J. Kim, C.F. Libaque-saenz \& Y. Chang, "Telematics and Informatics Use and gratifications of mobile SNSs: Facebook and KakaoTalk in Korea". Telemat. and inform., vol 32(3), p. 425-438, 2015.

[20] N. Kock, "Advanced mediating effects tests, multi-group analyses, and measurement model assessments in PLS-based SEM. Laredo", TX: Scr. Warp Syst., 2013

[21] N. Kock , \& L. Gaskins, "The mediating role of voice and accountability in the relationship between Internet diffusion and government corruption in Latin America and Sub-Saharan Africa.", Inform. Tech. for Dev., vol. 20(1), 23-43, 2014.

[22] N. Kock, "WarpPLS 5.0 User Manual. Laredo", TX: Scr. Warp Syst., 2015

[23] A. L. Becker, "Effect Size (ES)", http://web.uccs.edu/lbecker/Psy590/es.htm, 2000.

\section{REFERENCES}

[1] Alexa, 2018. www.alexa.com/topsites/countries/IDhttps://www.alexa.com/topsites/co untries/ID

[2] Z. Papacharissi , \& A. Rubin, M., "Predictors of Internet use. Journal of Broadcasting \& Electronic Media”, vol. 44,pp 175-196, 2000.

[3] W.G. Mangold, and D.J. Faulds, "Social media: the new hybrid element of the promotion mix," Bus. Horizons, Vol. 52 No. 4, pp. 357-365, 2009. 